\title{
ANÁLISE DAS COMPLICAÇÕES PÓS-OPERATÓRIAS DE GASTRECTOMIAS E FATORES ASSOCIADOS
}

\section{ARTIGO DE REVISÃO}

PEREIRA, Fernanda Cândido ${ }^{1}$

MOREIRA, Geterson Bezerra ${ }^{2}$

MELO, Andresa Mayra de Sousa ${ }^{3}$

PONTE NETO, Francisco Amaury Vasconcelos ${ }^{4}$

MENDONÇA, José Arthur Barreto Alves e ${ }^{5}$

MARTINS, Letícia Carvalho ${ }^{6}$

PAIXÃO, Marcos Roberto Diógenes ${ }^{7}$

MELO, Michelle Freitas ${ }^{8}$

${ }_{1}^{1}$ Discente do curso de Medicina do Centro Universitário UNINTA, Sobral - CE.

2 Orientador. Docente do curso de Medicina do Centro Universitário UNINTA, SobralCE. Cirurgião geral pela Santa Casa de Misericórdia de Sobral- Ceará. Coordenador da residência de Cirurgia da Santa Casa de Misericórdia de Sobral- UFC, SobralCeará.

${ }^{3}$ Discente do curso de Medicina do Centro Universitário UNINTA, Sobral - CE.

${ }^{4}$ Discente do curso de Medicina do Centro Universitário UNINTA, Sobral - CE.

${ }^{5}$ Discente do curso de Medicina do Centro Universitário UNINTA, Sobral - CE.

${ }^{6}$ Discente do curso de Medicina da Universidade CEUMA, São Luís, MA.

7 Discente do curso de Medicina do Centro Universitário UNINTA, Sobral - CE.

${ }^{8}$ Discente do curso de Medicina do Centro Universitário UNINTA, Sobral - CE. 
STUDNICKA, Natalli ${ }^{9}$

NOGUEIRA, Victor Matheus Gouveia ${ }^{10}$

MOURA, Daiane Dias de ${ }^{11}$

PEREIRA, Fernanda Cândido. Et al. Análise das complicações pós-operatórias de gastrectomias e fatores associados. Revista Científica Multidisciplinar Núcleo do Conhecimento. Ano 05, Ed. 10, Vol. 17, pp. 37-68. Outubro de 2020. ISSN: 24480959, Link de acesso: https://www.nucleodoconhecimento.com.br/saude/analise-dascomplicacoes

\section{RESUMO}

Introdução: A gastrectomia é um procedimento cirúrgico que consiste na retirada parcial ou completa do estômago. Suas principais indicações são o câncer gástrico, as complicações da doença ulcerosa péptica e o tratamento da obesidade mórbida. As gastrectomias, cirurgias de grande porte, possuem significativas taxas de morbidade e são passíveis de complicações, que podem conferir alto risco de morte ao paciente, exigindo intervenção em caráter de urgência. Assim, este estudo objetiva analisar e discutir as complicações das gastrectomias, descritas na literatura atual, e os fatores relacionados a elas. Métodos: A busca dos artigos foi realizada por meio do acesso à base de dados PubMed, com os descritores contidos no DeCS (Descritores em Ciências da Saúde), condizentes à temática da pesquisa e referentes aos termos: "cirurgia", "gastrectomia", "complicações pós-operatórias", "obesidade", "síndrome pós-gastrectomia", "úlcera gástrica" e "neoplasias gástricas", que associados aos operadores booleanos "AND" e "OR" proporcionaram a elaboração da fórmula de

9 Discente do curso de Medicina da Universidade do Extremo Sul Catarinense, Criciúma-Santa Catarina.

10 Discente do curso de Medicina do Centro Universitário UNINTA, Sobral - CE.

11 Discente do curso de Medicina da Universidade do Sul de Santa Catarina - Palhoça, Santa Catarina, Brasil. 
pesquisa utilizada. A busca resultou em um total de 96 artigos na base de dados, aos quais foram aplicados os critérios de inclusão e exclusão e, por fim, 21 artigos foram incluídos na presente revisão. Resultados: Dentre os estudos analisados, $57,14 \%$ dos artigos $(n=12)$ abordaram complicações das gastrectomias para o tratamento do câncer gástrico e 42,86\% (n=9) para o tratamento da obesidade. Peritonite, devido à formação de fístula anastomótica ou deiscência da ferida, foi a complicação geral precoce mais relatada pelos estudos. Concentração de PCR (proteína C reativa), albumina, relação PCR/albumina, idade, comorbidades, estádio do câncer gástrico, estado nutricional, dia da semana em que é realizada a cirurgia, entre outros fatores, foram apontados pelos estudos como preditores de complicações pós-operatórias das gastrectomias. Conclusões: Diante dos principais achados do presente estudo, reforça-se a relevância de os cirurgiões conhecerem as complicações das gastrectomias, em termos de frequência e gravidade, e os fatores relacionados a elas, a fim de evitar essas intercorrências ou tratá-las oportunamente, elevando a sobrevida dos pacientes.

Palavras-Chave: Gastrectomia, complicações pós-operatórias, obesidade, neoplasias gástricas.

\section{INTRODUÇÃO}

A gastrectomia é um procedimento cirúrgico que consiste na retirada parcial ou completa do estômago, com reconstrução do trânsito gastrointestinal. As técnicas de Billroth são utilizadas para a reconstrução do trato digestivo, sendo a do tipo 1, a anastomose com o duodeno, e a do tipo 2, com o jejuno. As principais indicações para a realização dessa cirurgia são o câncer gástrico, as complicações da doença ulcerosa péptica, como hemorragias refratárias ao tratamento clínico ou endoscópico, perfurações e estenoses, e, mais recentemente, o tratamento definitivo da obesidade mórbida.

O câncer gástrico é o quinto câncer mais comum, com mais de 900.000 novos casos a cada ano, e a terceira principal causa de morte por câncer em todo o mundo (NORERO et al., 2019). A gastrectomia com linfadenectomia é a única modalidade de 
tratamento que oferece esperança de controle da doença, melhor probabilidade de cura e elevação da sobrevida. A primeira ressecção gástrica por câncer foi realizada em 1881, pelo cirurgião alemão Billroth, e a primeira gastrectomia total em 1897, por Karl Schlatter (DUARTE et al., 2007). No Brasil, a gastrectomia com intuito curativo para os tumores gástricos foi introduzida no ano de 1900, em São Paulo, pelo cirurgião Arnaldo Vieira de Carvalho, e difundida por Paulino. Desde então, passou a ser empregada rotineiramente no tratamento do câncer, embora as taxas de complicações fossem muito elevadas. (ANDREOLLO et al., 2011).

A gastrectomia total é uma cirurgia de alto nível de complexidade, apresentando índices significativos de morbidade e mortalidade (ANDREOLLO et al., 2011). No tratamento do câncer gástrico, em particular, as complicações das gastrectomias tornam-se mais frequentes e mais graves, tanto localmente como sistemicamente, uma vez que o paciente, na maioria das vezes, tem suas condições clínicas e nutricionais comprometidas pela doença. Ademais, o tempo de hospitalização é maior e exige rigorosos cuidados pós-operatórios, além de controles de infecção, manutenção do estado geral e realimentação. (ANDREOLLO et al., 2011).

Atualmente, a obesidade é condição responsável por grande número de gastrectomias. Segundo a Organização Mundial de Saúde (OMS), no mundo, há mais de um bilhão de adultos com sobrepeso e 300 milhões com obesidade, a qual, desde 1991, tem sido considerada, pela OMS, uma doença crônica e de difícil controle. O insucesso da mudança do estilo de vida, das medidas comportamentais propostas e do tratamento clínico da obesidade incitou a necessidade de se pensar o tratamento cirúrgico. Diferentes técnicas foram elaboradas, sendo a gastrectomia vertical (GV) ou sleeve gástrico, uma das modalidades da cirurgia bariátrica mais realizadas atualmente. É considerado um procedimento primário para o tratamento cirúrgico da obesidade, com aumento da incidência de sua realização nos últimos anos.

A GV consiste na secção vertical e remoção da grande curvatura do estômago, com grampeamento e reforço com sobressutura, tornando o órgão tubular e alongado, de volume reduzido, a fim de proporcionar uma restrição alimentar importante. É um procedimento puramente restritivo, indicado para todos os tipos de pacientes obesos 
e a capacidade final de volume gástrico é de 150 a 200 ml. (BRANCO-FILHO et al., 2014)

Algumas condições inerentes à essa cirurgia podem resultar em complicações perioperatórias. Entre as mais frequentes estão a lesão do baço à dissecção periesplênica, as estenoses, isquemia e dificuldade de cicatrização adequada após o grampeamento sem o devido espaçamento, com consequente formação de fístula. Além disso, eventuais áreas de estreitamento somadas à alta pressão intra-gástrica e má cicatrização, podem ocasionar a perda da integridade da linha de grampos e sutura, resultando em deiscência ou rompimento da síntese cirúrgica e quadro de abdome agudo, conferindo alto risco de morte ao paciente e exigindo intervenção em caráter de urgência (CORREIA, 2014). Diante disso, ressalta-se que a gastrectomia vertical para o tratamento da obesidade, apesar de apresentar bons resultados e menor taxa de morbimortalidade, não é isenta de complicações. Assim, faz-se importante observá-las acerca de sua epidemiologia e fatores predisponentes, a fim de intervir de modo a reduzir essas intercorrências.

As gastrectomias para o tratamento das complicações da doença ulcerosa péptica (DUP) têm diminuído drasticamente nas últimas décadas. Há 20 ou 30 anos era frequentemente realizada pelos cirurgiões durante o programa de treinamento. Com o advento dos medicamentos antiulcerosos e do tratamento do H. Pilory, os índices de cura da DUP chegaram a mais de $90 \%$, restando, assim, poucos casos para serem resolvidos pelo cirurgião (ILIAS, 2011). As possíveis indicações de gastrectomia nos casos de úlcera péptica complicados ou que não respondem ao tratamento clínico são a úlcera perfurada, obstrução piloro-duodenal, hemorragia digestiva com ressangramento ou isquemia gástrica ou duodenal mesmo após a terapia endoscópica e, mais raramente, a intratabilidade clínica. Nos casos em que o tratamento clínico não resulta em melhora, o tratamento cirúrgico se faz necessário, sobretudo em casos de úlcera gástrica, que é passível de malignização, devendo ser tratada por 4 a 8 semanas, e, se não houver remissão importante ou cura, a gastrectomia deve ser indicada. (ILIAS, 2011). 
As taxas de morbidade pós-operatória após gastrectomias variam entre diferentes estudos, mas a morbidade total é superior a 20-30\% na maioria dos estudos. Na última década, a gravidade das complicações ganhou grande importância e foi adotado o uso da escala de Clavien-Dindo para classificá-las. No entanto, apenas alguns estudos avaliaram preditores de morbidade no pós-operatório de acordo com a gravidade da complicação para gastrectomia (NORERO et al, 2019). Assim, as gastrectomias, cirurgias de grande porte, possuem significativas taxas de morbidade e são passíveis de complicações, sendo algumas mais frequentes e outras mais raras, mas que podem acrescentar significativa morbidade ao paciente ou, até mesmo, serem potencialmente fatais. Diante disso, se faz necessário que haja estudos de análise e discussão dessas complicações, e dos fatores relacionados a elas, a fim de que se possa aumentar o conhecimento acerca do assunto, para que, na prática clínico-cirúrgica, os profissionais possam reconhecê-las precocemente para tratá-las oportunamente, evitando 0 aumento da morbimortalidade associada às gastrectomias. Nesse sentido, surge a seguinte questão: "Quais as complicações pósoperatórias de gastrectomias, descritas na literatura atual, e os fatores relacionados a elas?"

Diante dessas perspectivas, a pesquisa tem como objetivo primordial apontar, analisar e discutir as complicações das gastrectomias, descritas na literatura atual, e os fatores relacionados a elas.

\section{DESENVOLVIMENTO}

\section{METODOLOGIA}

Caracteriza-se como uma revisão bibliográfica do tipo integrativa, de abordagem qualitativa e natureza aplicada, objetivando a descrição da análise de dados coletados sobre os fatores associados e as complicações relatadas no pós-operatório de Gastrectomias.

A busca dos artigos foi realizada por meio do acesso à base de dados PubMed. Para isso, utilizou-se de descritores, contidos no DeCS (Descritores em Ciências da 
Saúde), condizentes à temática da pesquisa e referentes aos termos: "cirurgia", "gastrectomia", "complicações pós-operatórias", "obesidade", "síndrome pósgastrectomia", "úlcera gástrica" e "neoplasias gástricas". Tais descritores, empregados em português, inglês e espanhol e associados aos operadores booleanos "AND" e "OR" proporcionaram a elaboração da fórmula de pesquisa utilizada.

A busca realizada encontrou um total de 96 artigos na base de dados consultada, sendo selecionados por meio da leitura do título e resumo os textos que abordaram as complicações pós-operatórias de gastrectomias. Os critérios de inclusão empregados foram: artigos que retratassem temática convergente aos objetivos da pesquisa, escritos em português, inglês e espanhol, realizados em humanos e indexados na base de dados entre os anos 2015 a 2020, estando disponíveis na íntegra. Ademais, os critérios de exclusão descartaram artigos não disponíveis na íntegra e os que não atendiam à finalidade da pesquisa.

Dessa forma, ressaltamos que a pesquisa não apresenta caráter prático, não havendo, portanto, a necessidade de submissão ao Comitê de Ética em Pesquisa (CEP).

Para a apresentação dos resultados desta revisão, os achados foram divididos conforme a temática e organizados em duas tabelas, a primeira retratando os dados encontrados sobre as complicações de gastrectomias em casos de obesidade e a segunda em casos de câncer gástrico. Nas tabelas foram retratadas as principais informações da amostra de artigos incluídos na revisão, como o nome dos autores, ano de publicação, país, tipo de estudo e os principais resultados encontrados em cada um deles. 


\section{RESULTADOS}

Tabela 1 - Principais resultados da pesquisa: Análise das complicações das gastrectomias por câncer e seus fatores associados.

\begin{tabular}{|c|c|c|c|c|}
\hline Título do Artigo & $\begin{array}{l}\text { Autor, ano } \\
\text { da } \\
\text { publicação }\end{array}$ & $\begin{array}{l}\text { País de } \\
\text { origem }\end{array}$ & Intervenção & Resultados \\
\hline $\begin{array}{l}\text { Capacidade das } \\
\text { concentrações } \\
\text { séricas de } \\
\text { proteína C reativa } \\
\text { para prever } \\
\text { complicações } \\
\text { após gastrectomia } \\
\text { assistida por } \\
\text { laparoscopia: um } \\
\text { estudo de coorte } \\
\text { prospectivo }\end{array}$ & $\begin{array}{l}\text { Zhang et } \\
\text { al., } 2016\end{array}$ & China & $\begin{array}{l}\text { Gastrectomia } \\
\text { laparoscópica } \\
\text { (LAG) para } \\
\text { câncer gástrico }\end{array}$ & 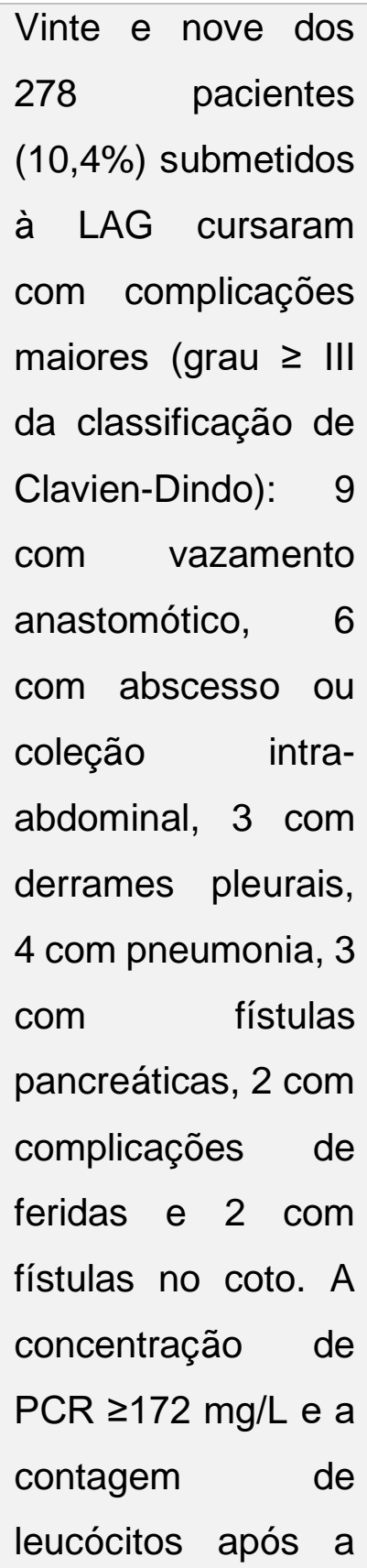 \\
\hline
\end{tabular}




\begin{tabular}{|c|c|c|c|c|}
\hline & & & & $\begin{array}{l}\text { LAG tiveram a } \\
\text { maior precisão } \\
\text { diagnóstica para } \\
\text { complicações } \\
\text { maiores, } \\
\text { configurando-se } \\
\text { como fatores de } \\
\text { risco. }\end{array}$ \\
\hline \begin{tabular}{l}
\multicolumn{2}{l}{ Gastrectomia } \\
proximal versus \\
total para câncer \\
gástrico proximal \\
inicial: uma \\
revisão \\
sistemática \\
meta-análise
\end{tabular} & $\begin{array}{l}\text { Xu et al., } \\
2019\end{array}$ & China & $\begin{array}{l}\text { Gastrectomia } \\
\text { proximal (GP) } \\
\text { e gastrectomia } \\
\text { total (GT) para } \\
\text { câncer gástrico }\end{array}$ & 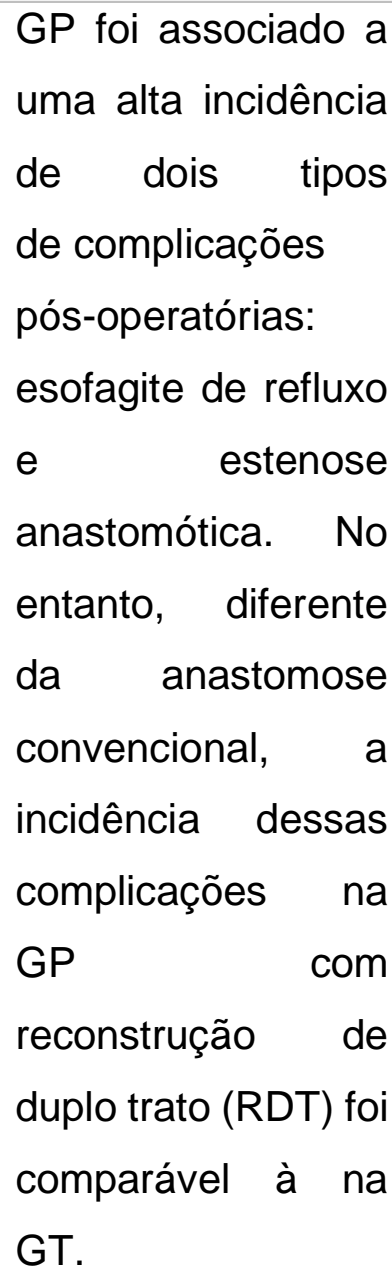 \\
\hline $\begin{array}{l}\text { Nomograma para } \\
\text { prever íleo pós- } \\
\text { operatório } \\
\text { prolongado após }\end{array}$ & $\begin{array}{l}\text { Liang et } \\
\text { al., } 2019\end{array}$ & China & $\begin{array}{l}\text { Gastrectomia } \\
\text { radical para } \\
\text { câncer gástrico } \\
(\mathrm{CG})\end{array}$ & $\begin{array}{l}\text { A incidência de íleo } \\
\text { pós-operatório } \\
\text { prolongado (PPOI) } \\
\text { foi de } 19,75 \% \text {. } \\
\text { ldade maior que } 60\end{array}$ \\
\hline
\end{tabular}




\begin{tabular}{|c|c|c|c|c|}
\hline $\begin{array}{l}\text { gastrectomia em } \\
\text { câncer gástrico }\end{array}$ & & & & $\begin{array}{l}\text { anos, cirurgia } \\
\text { aberta, estágio } \\
\text { avançado (III-IV) e } \\
\text { uso pós-operatório } \\
\text { de opióide foram } \\
\text { fatores de risco } \\
\text { independentes para } \\
\text { IBPI. }\end{array}$ \\
\hline $\begin{array}{l}\text { Tratamento da } \\
\text { fístula do coto } \\
\text { duodenal após } \\
\text { gastrectomia para } \\
\text { doença maligna: } \\
\text { uma revisão } \\
\text { sistemática da } \\
\text { literatura }\end{array}$ & $\begin{array}{l}\text { Zizzo et } \\
\text { al., } 2019\end{array}$ & Itália & $\begin{array}{l}\text { Gastrectomia } \\
\text { subtotal ou } \\
\text { total para } \\
\text { câncer gástrico }\end{array}$ & $\begin{array}{l}\text { Fístula do coto } \\
\text { duodenal (FCD) é } \\
\text { complicação rara, } \\
\text { mas potencialmente } \\
\text { letal, } \\
\text { gastrectomias. } \\
\text { diagnóstico ocorreu } \\
\text { entre o } 5^{\circ} \text { e o 10 } \\
\text { DPO. As principais } \\
\text { complicações } \\
\text { relacionadas foram } \\
\text { sepse, abscesso } \\
\text { abdominal, infecção } \\
\text { da ferida, } \\
\text { pneumonia } \\
\text { sangramento intra- } \\
\text { abdominal. } \\
\text { mortalidade } \\
\text { relacionada à FCD } \\
\text { registrou 18,7\%. }\end{array}$ \\
\hline $\begin{array}{l}\text { Impacto da } \\
\text { gastrectomia total } \\
\text { com preservação }\end{array}$ & $\begin{array}{l}\text { Aiolfi et al., } \\
2019\end{array}$ & Milão & $\begin{array}{l}\text { Gastrectomia } \\
\text { total aberta, } \\
\text { com ou sem }\end{array}$ & $\begin{array}{l}\text { As taxas de } \\
\text { complicações } \\
\text { infecciosas pós- }\end{array}$ \\
\hline
\end{tabular}




\begin{tabular}{|c|c|c|c|c|}
\hline 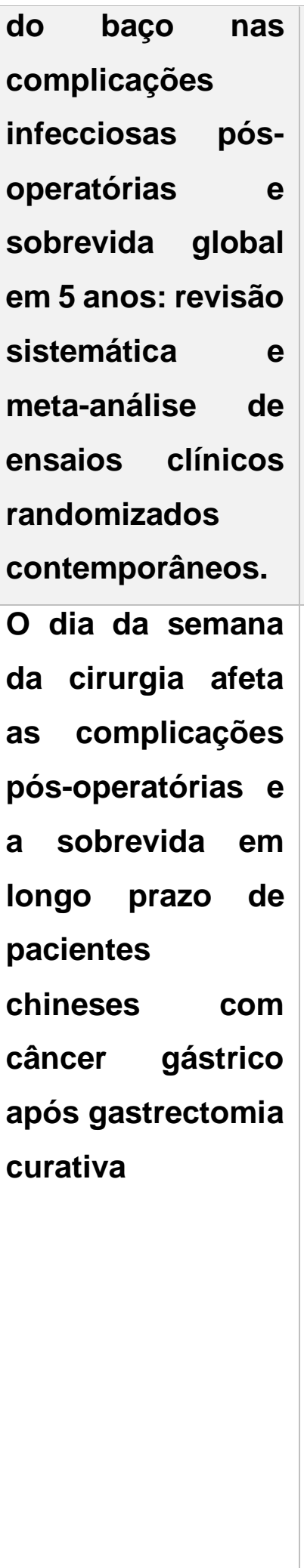 & $\begin{array}{l}\text { Li et al., } \\
2017\end{array}$ & China & $\begin{array}{l}\text { esplenectomia, } \\
\text { para câncer }\end{array}$ & 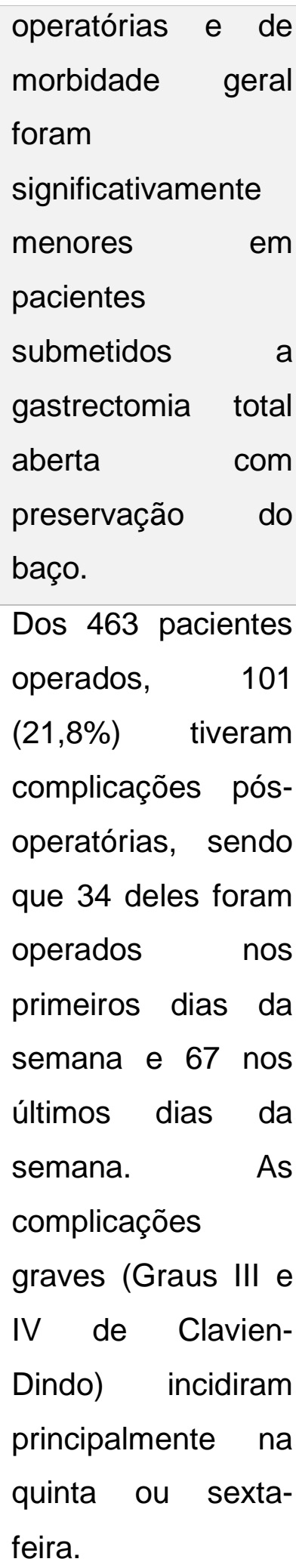 \\
\hline
\end{tabular}




\begin{tabular}{|c|c|c|c|c|}
\hline $\begin{array}{l}\text { A composição } \\
\text { corporal } \\
\text { quantificada por } \\
\text { tomografia } \\
\text { computadorizada } \\
\text { prediz resultados } \\
\text { de curto prazo } \\
\text { após gastrectomia } \\
\text { em câncer } \\
\text { gástrico }\end{array}$ & $\begin{array}{l}\text { Zhang et } \\
\text { al., } 2018\end{array}$ & China & $\begin{array}{l}\text { Gastrectomia } \\
\text { para câncer } \\
\text { gástrico }\end{array}$ & $\begin{array}{l}\text { A taxa geral de } \\
\text { complicações foi } \\
\text { significativamente } \\
\text { maior nos grupos de } \\
\text { sarcopenia } \\
\text { miosteatose. } \\
\text { Pacientes } \\
\text { obesidade visceral } \\
\text { apresentaram maior } \\
\text { incidência } \\
\text { complicações } \\
\text { inflamatórias. } \\
\text { Sarcopenia, } \\
\text { miosteatose e baixa } \\
\text { proteína sérica de } \\
\text { ligação ao retinol } \\
\text { foram fatores de } \\
\text { risco independentes } \\
\text { para complicações } \\
\text { gerais. }\end{array}$ \\
\hline $\begin{array}{l}\text { Fatores de risco } \\
\text { para } \\
\text { complicações da } \\
\text { gastrectomia total } \\
\text { / subtotal para } \\
\text { câncer gástrico: } \\
\text { coletados } \\
\text { prospectivamente, } \\
\text { com base no } \\
\text { sistema de }\end{array}$ & $\begin{array}{l}\text { Nevo et } \\
\text { al., } 2018\end{array}$ & Israel & $\begin{array}{l}\text { Gastrectomia } \\
\text { total e subtotal } \\
\text { para câncer }\end{array}$ & $\begin{array}{l}\text { O estudo envolveu } \\
112 \text { pacientes; } 53 \\
\text { pacientes (47\%) } \\
\text { foram submetidos a } \\
\text { gastrectomia, } 37 \\
\text { (34\%) gastrectomia } \\
\text { total e } 22 \text { (19\%) } \\
\text { gastrectomia total } \\
\text { estendida. Todos os } \\
\text { pacientes foram } \\
\text { submetidos à }\end{array}$ \\
\hline
\end{tabular}




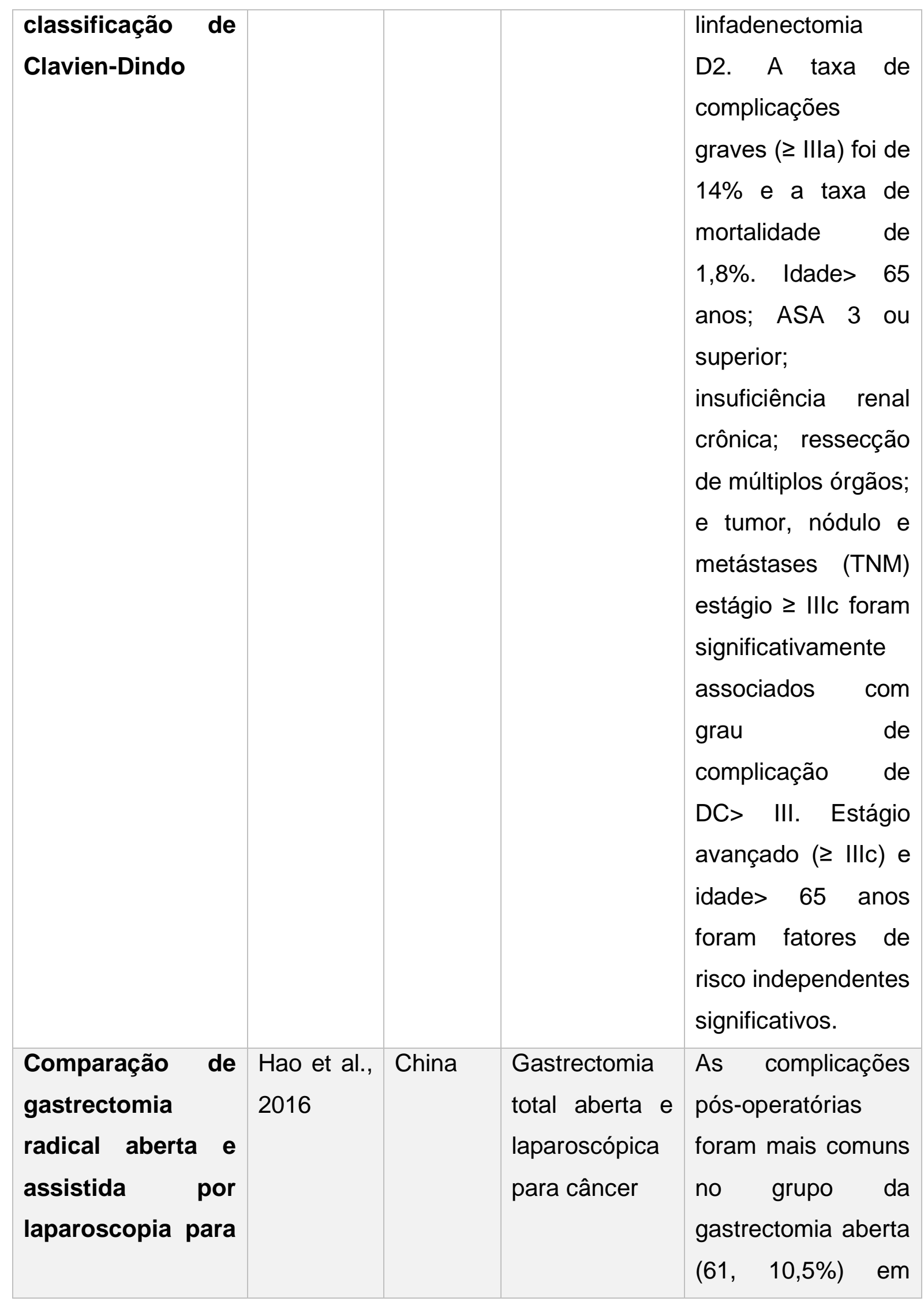




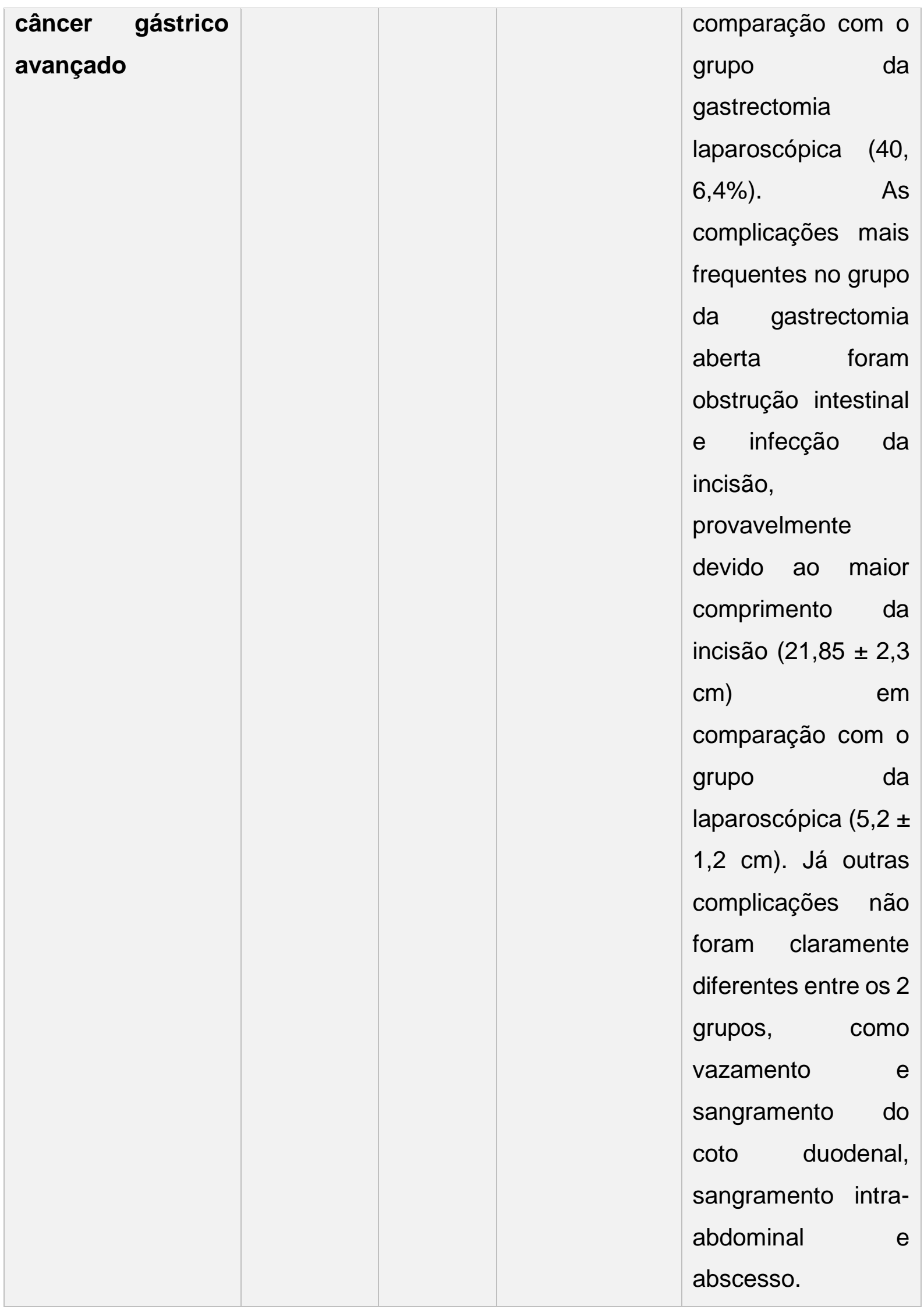




\begin{tabular}{|c|c|c|c|c|}
\hline $\begin{array}{l}\text { Fístula duodenal } \\
\text { após } \\
\text { gastrectomia: } \\
\text { estudo } \\
\text { retrospectivo de } \\
13 \text { novos casos }\end{array}$ & $\begin{array}{l}\text { Cornejo et } \\
\text { al., } 2016\end{array}$ & Espanha & $\begin{array}{l}\text { Gastrectomia } \\
\text { para câncer } \\
\text { gástrico }\end{array}$ & 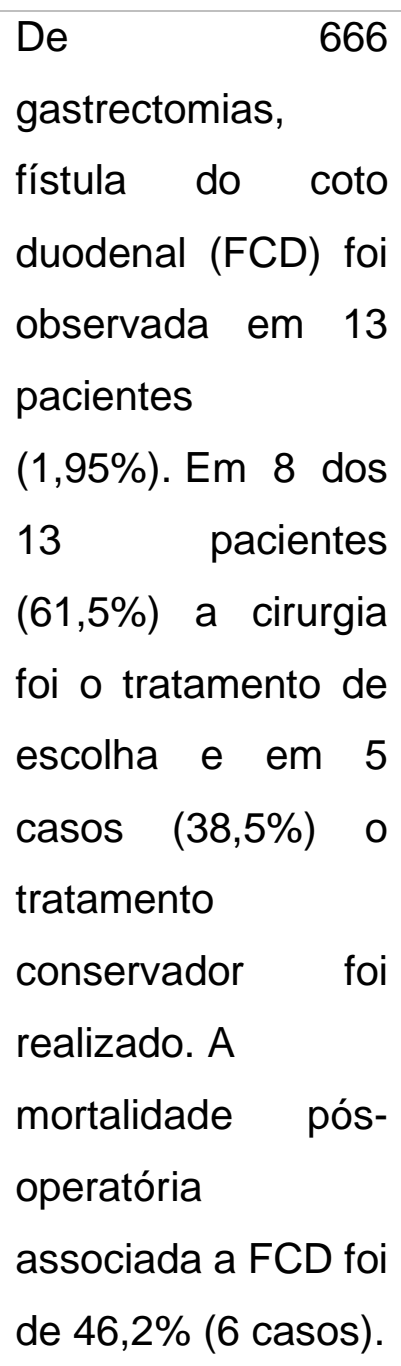 \\
\hline $\begin{array}{l}\text { Razão proteína C } \\
\text { reativa / albumina } \\
\text { pós-operatória } \\
\text { como um novo } \\
\text { preditor de } \\
\text { complicações de } \\
\text { curto prazo após } \\
\text { gastrectomia de } \\
\text { câncer gástrico }\end{array}$ & $\begin{array}{l}\text { Sun et al. } \\
2017\end{array}$ & China & $\begin{array}{l}\text { Gastrectomia } \\
\text { para câncer } \\
\text { gástrico }\end{array}$ & 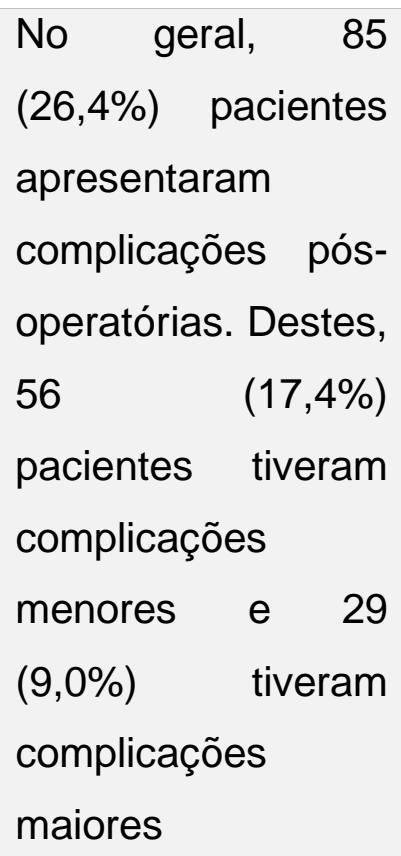 \\
\hline
\end{tabular}




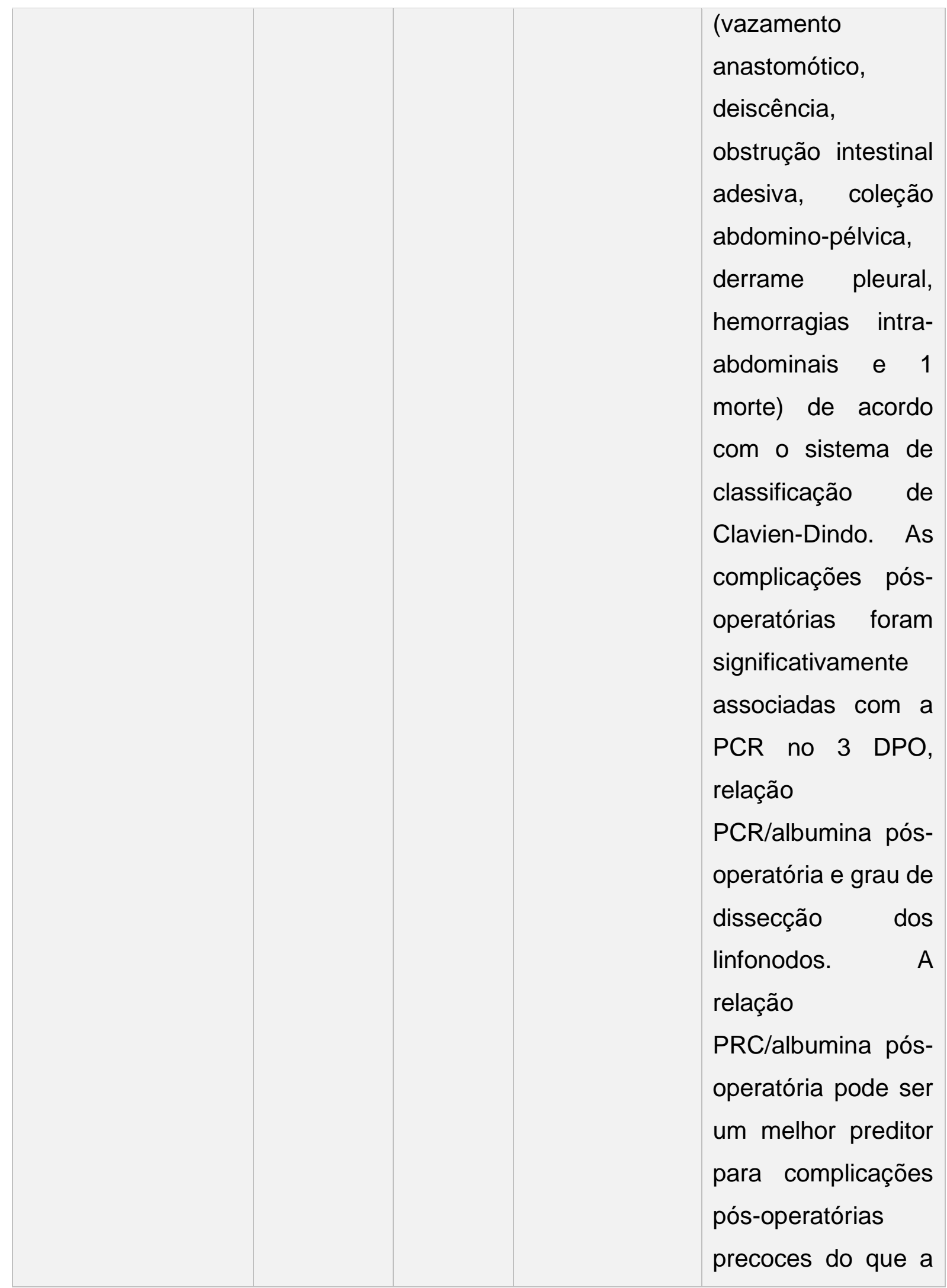




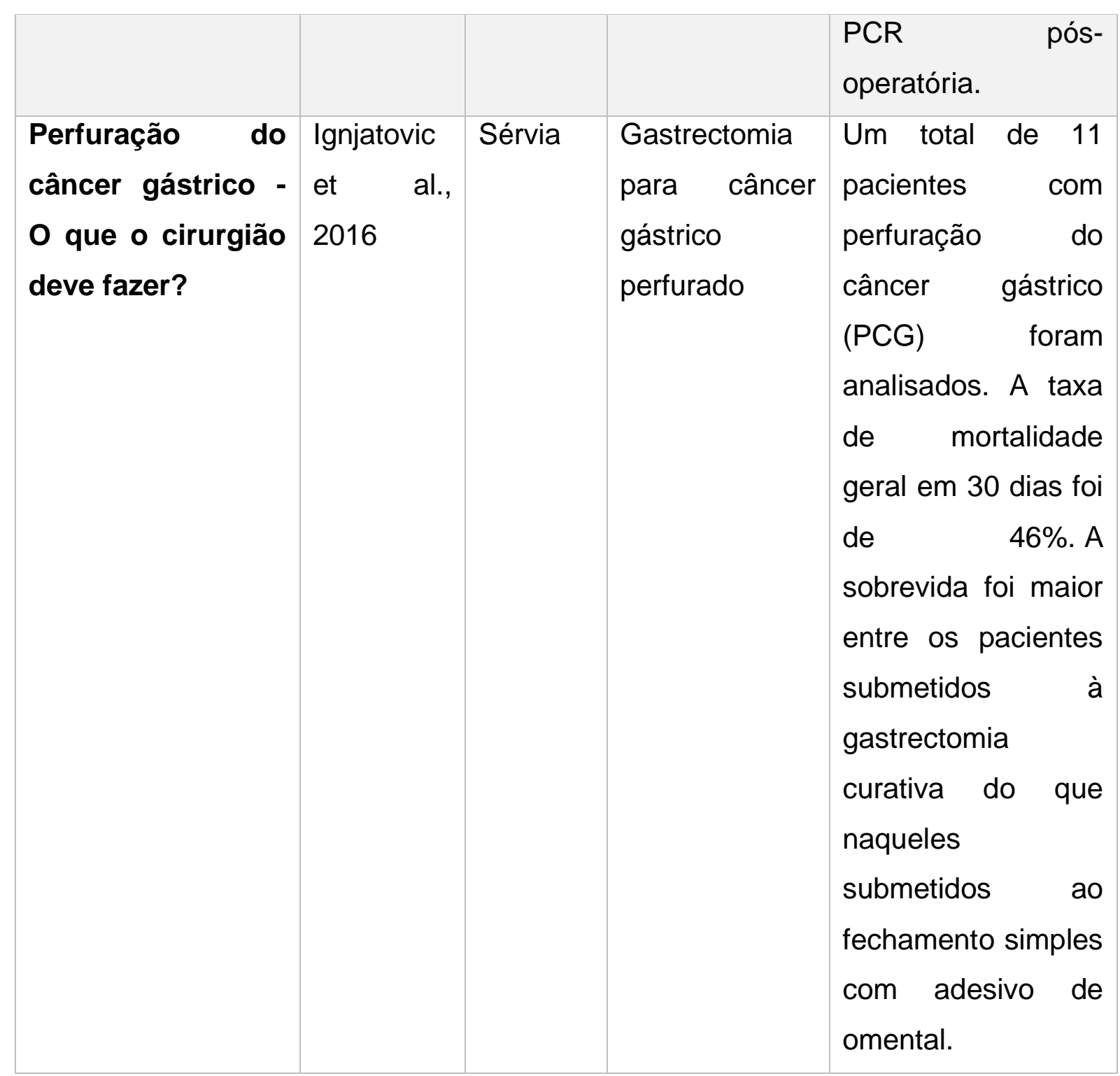

Tabela 2 - Principais resultados da pesquisa: Análise das complicações das gastrectomias por obesidade e seus fatores associados

\begin{tabular}{|c|c|c|}
\hline $\begin{array}{l}\text { Autor, ano da } \\
\text { publicação }\end{array}$ & Intervenção & Resultados \\
\hline $\begin{array}{l}\text { KASSIR et } \\
\text { al., } 2016\end{array}$ & $\begin{array}{l}\text { Gastrectomia } \\
\text { vertical para } \\
\text { obesidade }\end{array}$ & $\begin{array}{l}\text { A complicação mais comum após a cirurgia } \\
\text { bariátrica é a peritonite secundária à fístula } \\
\text { anastomótica. Tem uma incidência de } 3-7 \% \\
\text { após gastrectomia vertical e ocorre } \\
\text { tipicamente como uma complicação precoce, }\end{array}$ \\
\hline
\end{tabular}




\begin{tabular}{|c|c|c|}
\hline & & $\begin{array}{l}\text { mas pode se desenvolver até } 3 \text { meses após. } \\
\text { O sangramento pode ocorrer nas linhas de } \\
\text { grampo do trato gastrointestinal ou nas } \\
\text { anastomoses, em cerca de } 2 \% \text { dos } \\
\text { pacientes. }\end{array}$ \\
\hline $\begin{array}{l}\text { Major et al., } \\
2018\end{array}$ & $\begin{array}{l}\text { Gastrectomia } \\
\text { vertical } \\
\text { laparoscópica } \\
\text { (LSG) e Bypass } \\
\text { gástrico } \\
\text { laparoscópico em Y } \\
\text { de Roux (LRYGB) } \\
\text { para obesidade }\end{array}$ & $\begin{array}{l}\text { Maior risco de náuseas e vômitos pós- } \\
\text { operatórios no grupo LSG. Taxas de } \\
\text { complicações pós-operatórias gerais e } \\
\text { específicas, incluindo vazamento } \\
\text { gastrointestinal, estenose, infecção da ferida } \\
\text { e pneumonia, não foram relacionadas ao tipo } \\
\text { de procedimento bariátrico realizado. Não } \\
\text { houve diferenças significativas na gravidade } \\
\text { das complicações, avaliadas de acordo com } \\
\text { a classificação de Clavien-Dindo, entre os } \\
\text { dois grupos. }\end{array}$ \\
\hline $\begin{array}{l}\text { Hans et al., } \\
2018\end{array}$ & $\begin{array}{l}\text { Gastrectomia } \\
\text { vertical } \\
\text { laparoscópica para } \\
\text { obesidade }\end{array}$ & $\begin{array}{l}\text { Dentre os } 218 \text { pacientes operados no } \\
\text { período, não houve complicações } \\
\text { maiores, reoperações ou } \\
\text { mortalidade. A complicação } \\
\text { operatória precoce mais comum foi a } \\
\text { deiscência da ferida no local do ponto, } \\
\text { ocorrida em um ou mais locais do ponto em } \\
21 \text { pacientes (10\%). Dos } 10 \text { pacientes que } \\
\text { sofreram de vômitos e náuseas prolongadas, } \\
4 \text { necessitaram de readmissão (1,83\%) } \\
\text { devido à desidratação em } 30 \text { dias da cirurgia. }\end{array}$ \\
\hline $\begin{array}{l}\text { Wang et al., } \\
2016\end{array}$ & $\begin{array}{l}\text { Gastrectomia } \\
\text { vertical } \\
\text { laparoscópica para } \\
\text { obesidade }\end{array}$ & $\begin{array}{l}\text { Setenta pacientes foram submetidos a } \\
\text { gastrectomia vertical laparoscópica. Houve } \\
\text { uma conversão para cirurgia aberta devido } \\
\text { ao hemoperitônio }(1,4 \%) \text {. Nenhuma }\end{array}$ \\
\hline
\end{tabular}




\begin{tabular}{|c|c|c|}
\hline & & $\begin{array}{l}\text { mortalidade foi relatada durante } 0 \\
\text { seguimento, mas complicações precoces } \\
\text { ocorreram em } 6(8,6 \%) \text { pacientes, sendo elas } \\
\text { hemoperitônio, vazamento, infecção de ferida } \\
\text { e lesão esplênica. Complicações tardias } \\
\text { ocorreram em } 5(7,1 \%) \text { pacientes. }\end{array}$ \\
\hline $\begin{array}{l}\text { Diaz et al., } \\
2015\end{array}$ & $\begin{array}{l}\text { Gastrectomía } \\
\text { vertical } \\
\text { laparoscópica para } \\
\text { obesidade }\end{array}$ & $\begin{array}{l}\text { Dos } 73 \text { pacientes operados, } 5 \text { (6,85\%) } \\
\text { apresentaram complicações: } 3 \text { fístulas no } \\
\text { pós-operatório (4,1\%), uma estenose } \\
\text { completa }(1,4 \%) \text { e um sangramento pós- } \\
\text { operatório }(1,4 \%) \text { sem sinais de repercussão } \\
\text { hemodinâmica. Todas as complicações } \\
\text { ocorreram durante as primeiras } 25 \\
\text { intervenções da curva de } \\
\text { aprendizado. Todos os } 73 \text { pacientes } \\
\text { completaram o acompanhamento de } 12 \\
\text { meses e nenhum paciente morreu durante } \\
\text { este período. }\end{array}$ \\
\hline $\begin{array}{l}\text { Vuono et al., } \\
2016\end{array}$ & $\begin{array}{l}\text { Gastrectomia } \\
\text { vertical } \\
\text { laparoscópica para } \\
\text { obesidade }\end{array}$ & $\begin{array}{l}\text { Todos os procedimentos foram regularmente } \\
\text { concluídos com abordagem laparoscópica } \\
\text { sem conversão para laparotomia. } \\
\text { Complicações pós-operatórias ocorreram em } \\
\text { seis pacientes }(3,7 \%) \text {; nenhuma mortalidade } \\
\text { pós-operatória foi observada. Três pacientes } \\
\text { apresentaram sangramento precoce }(1,9 \%) \text {, } \\
1 \text { apresentou estenose }(0,9 \%), 1 \text { apresentou } \\
\text { vazamento }(0,9 \%) \text { e outro apresentou } \\
\text { abscesso }(0,9 \%) \text {. }\end{array}$ \\
\hline $\begin{array}{l}\text { Mcheimeche } \\
\text { et al., } 2018\end{array}$ & $\begin{array}{l}\text { Gastrectomia } \\
\text { vertical }\end{array}$ & $\begin{array}{l}\text { Dupla fístulojejunostomia foi uma técnica } \\
\text { viável, sem complicações intra-operatórias } \\
\text { para o tratamento de duas fístulas gástricas }\end{array}$ \\
\hline
\end{tabular}




\begin{tabular}{|c|c|c|}
\hline & $\begin{array}{l}\text { laparoscópica para } \\
\text { obesidade }\end{array}$ & $\begin{array}{l}\text { após gastrectomia vertical. No pós- } \\
\text { operatório, o paciente teve uma boa } \\
\text { recuperação, sem vazamento residual. A } \\
\text { técnica de Baltazar duplo é uma opção de } \\
\text { tratamento bem-sucedida e permite evitar } \\
\text { opções cirúrgicas mais agressivas, como } \\
\text { gastrectomia total ou bypass gástrico. }\end{array}$ \\
\hline $\begin{array}{l}\text { Giménez et } \\
\text { al., } 2017\end{array}$ & $\begin{array}{l}\text { Gastrectomia } \\
\text { vertical } \\
\text { laparoscópica para } \\
\text { obesidade }\end{array}$ & $\begin{array}{l}\text { O infarto esplênico geralmente é uma } \\
\text { complicação precoce, mas devemos mantê- } \\
\text { lo em mente como uma complicação de longo } \\
\text { prazo para pacientes com febre persistente e } \\
\text { dor abdominal após gastrectomia } \\
\text { laparoscópica. }\end{array}$ \\
\hline $\begin{array}{l}\text { Oliveira } \\
\text { al,. } 2019\end{array}$ & $\begin{array}{l}\text { Gastrectomia } \\
\text { vertical aberta para } \\
\text { obesidade }\end{array}$ & $\begin{array}{l}\text { Dezesseis (5,4\%) pacientes tiveram } \\
\text { complicações precoces (até } 60 \text { dias após a } \\
\text { cirurgia), como infecção de sítio cirúrgico, } \\
\text { deiscência de ferida operatória, infecção do } \\
\text { trato urinário, sepse de foco pulmonar, } \\
\text { trombose venosa profunda (TVP), } \\
\text { tromboembolismo pulmonar (TEP) } \\
\text { deiscência de coto gástrico. Dessas } \\
\text { reinternações, } 11 \text { pacientes } \\
\text { necessitaram ser reoperados, sendo } 7 \text { (2,3\%) } \\
\text { por deiscência do coto gástrico. Três mortes } \\
\text { por complicações precoces foram } \\
\text { contabilizadas, o que representou uma taxa } \\
\text { de mortalidade de 1\%. }\end{array}$ \\
\hline
\end{tabular}

Foram incluídos 21 artigos na revisão. Dentre os estudos analisados, $57,14 \%$ dos artigos $(n=12)$ abordaram complicações das gastrectomias para o tratamento do câncer gástrico e 42,86\% (n=9) para o tratamento da obesidade. Um estudo da França que analisou as complicações após a cirurgia bariátrica mostrou que a complicação 
mais comum é a peritonite devido à formação de fístula anastomótica, com uma incidência de 3-7\% após gastrectomia vertical. Se não diagnosticada, a fístula resulta em sepse, que pode causar insuficiência renal e respiratória aguda. (KASSIR et al., 2016). Esse achado foi corroborado por um estudo prospectivo com 73 pacientes submetidos à gastrectomia vertical laparoscópica de fevereiro de 2009 a setembro de 2013, que apresentou como principal complicação as fístulas no pós-operatório $(4,1 \%)$, seguida de estenose completa $(1,4 \%)$ e sangramento pós-operatório $(1,4 \%)$. As fístulas foram diagnosticadas durante o acompanhamento ambulatorial com base no quadro clínico de peritonite e nos exames de imagem, sendo a tomografia computadorizada do abdome o mais indicado para o diagnóstico dessa complicação. (DIAZ et al., 2015). Um retrospectivo realizado em um centro de cirurgia bariátrica e metabólica na China, analisou 218 pacientes submetidos à gastrectomia vertical laparoscópica entre junho de 2011 a junho de 2016. A complicação pósoperatória precoce mais comum foi a deiscência da ferida no local do ponto e grampeamento, ocorrida em um ou mais locais da linha de grampos e sutura em 21 pacientes (10\%). (HANS et al., 2018).

Um estudo da China investigou as complicações após gastrectomia laparoscópica para câncer e a capacidade das concentrações de proteína $C$ reativa (PCR) e de leucócitos para a detecção precoce dessas complicações. Viu-se que 29 dos 278 pacientes $(10,4 \%)$ que se submeteram com sucesso à cirurgia desenvolveram complicações maiores (grau $\geq$ III da classificação de Clavien-Dindo). Dentre as complicações, 9 cursaram com vazamento anastomótico, 6 com abscesso intraabdominal ou coleções de fluidos, 3 com derrames pleurais, 4 com pneumonia, $3 \mathrm{com}$ fístulas pancreáticas, $2 \mathrm{com}$ complicações de feridas e $2 \mathrm{com}$ fístulas no coto. A concentração de PCR no 3 o dia de pós-operatório (DPO) e a contagem de leucócitos no $7^{\circ}$ DPO tiveram a maior precisão diagnóstica para complicações maiores. A análise multivariada identificou concentrações de PCR $\geq 172 \mathrm{mg} / \mathrm{L}$ no $3^{\circ}$ DPO como um dos fatores de risco para complicações maiores após a gastrectomia laparoscópica. (ZHANG et al., 2016). Esse resultado foi corroborado pela análise de Sun et al. 2017, que observou que as complicações pós-operatórias ocorridas em 85 pacientes $(26,4 \%)$ foram significativamente associadas com ao valor da PCR no 3 ํ DPO, e que 
a relação PRC/albumina pós-operatória pode ser um preditor ainda mais fidedigno para complicações precoces.

Uma análise comparativa entre gastrectomia proximal (GP) versus total (GT) para câncer gástrico proximal e complicações associadas, mostrou que, entre as complicações pós-operatórias, não houve diferença nas frequências de vazamento anastomótico, sangramento e fístula pancreática. A incidência de estenose anastomótica foi significativamente maior no grupo GP do que no grupo GT. (XU et al., 2019). Um estudo de 2019, investigou os fatores preditivos de íleo pós-operatório prolongado IPOP) em pacientes submetidos à gastrectomia radical para câncer. Observou-se incidência de IPOP de $19,75 \%$ e os fatores preditivos para essa complicação foram idade maior que 60 anos, cirurgia aberta, estágio avançado (III-IV) e uso pós-operatório de opióide. (Liang et al., 2019). Em nossa revisão, dois estudos analisaram a ocorrência da fístula do coto duodenal (FCD), uma complicação rara, mas potencialmente letal, das gastrectomias. Revisão sistemática da literatura publicada em 2019, que cobriu um período de estudo de aproximadamente 40 anos (1979-2017), com uma população total de 294 pacientes e 20 artigos incluídos, mostrou que os principais fatores relacionadas à FCD e que elevam a mortalidade, foram sepse, abscesso abdominal, infecção da ferida, pneumonia e sangramento intra-abdominal. A mortalidade relacionada à FCD foi de 18,7\%. (ZIZZO et al., 2019). Análise retrospectiva de todas as FCD ocorridas em um hospital da Espanha, após a realização de gastrectomia para câncer gástrico, observou que, das 666 gastrectomias, FCD ocorreu em 13 pacientes (1,95\%). A mortalidade pós-operatória associada a FCD foi de 46,2\% (6 casos). (CORNEJO et al., 2016). Revisão sistemática e meta-análise de ensaios clínicos randomizados contemporâneos, analisou o Impacto da gastrectomia total com preservação do baço nas complicações infecciosas pós-operatórias. Foram incluídos 899 pacientes. No geral, 451 pacientes $(50,1 \%)$ foram submetidos à gastrectomia total aberta com preservação do baço e 448 (49,9\%) à gastrectomia total aberta com esplenectomia. Viu-se que as taxas de complicações infecciosas pós-operatórias e de morbidade geral foram significativamente menores em pacientes submetidos a gastrectomia com preservação do baço. (AIOLFI et al., 2019). Uma análise retrospectiva de 463 pacientes que foram submetidos à 
gastrectomia para câncer gástrico durante o período de $1^{\circ}$ de janeiro de 2004 a $1^{\circ}$ de janeiro de 2010, no Departamento de Cirurgia Gastrointestinal, de um hospital da China, estudou a relação do dia da semana da operação com o índice de complicações. Os resultados mostraram que pacientes operados nos últimos dias da semana tiveram maior risco de sofrer complicações pós-operatórias. Foram 198 pacientes operados nos primeiros dias da semana (segunda ou terça-feira) e 265 pacientes nos últimos dias da semana (quarta a sexta). Do total de 463 pacientes, 101 $(21,8 \%)$ tiveram complicações pós-operatórias, sendo que 34 deles foram operados nos primeiros dias da semana e 67 nos últimos dias da semana. As complicações graves (Graus III e IV de Clavien-Dindo) incidiram principalmente na quinta ou sextafeira. (LI et al., 2017).

Em um trabalho de Zhang et al. (2018) obervou-se que a composição corporal pode predizer resultados de curto prazo após gastrectomias: sarcopenia, miosteatose e obesidade visceral foram significativamente associadas ao aumento das taxas de complicações pós-operatórias e afetaram a nutrição pós-operatória e o estado de inflamação de pacientes com câncer gástrico. Coorte retrospectiva com 112 pacientes submetidos à gastrectomia total, subtotal ou total estendida, para câncer, revelou uma taxa de complicações graves ( $\geq$ IIIa) foi de $14 \%$ e taxa de mortalidade de $1,8 \%$. Idade> 65 anos; ASA 3 ou superior; insuficiência renal crônica; ressecção de múltiplos órgãos; e tumor, nódulo e metástases (TNM) estágio $\geq$ IIIc foram significativamente associados com maior grau de complicação. (NEVO et al., 2018).

Para comparar os resultados das gastrectomias radicais aberta e laparoscópica, Hao et al. (2016) analisou 579 pacientes submetidos à técnica convencional e 628 submetidos à técnica minimamente invasiva, de janeiro de 2004 a dezembro de 2011. Corroborando resultados de estudos anteriores, as complicações pós-operatórias foram mais comuns no grupo da gastrectomia aberta $(61 ; 10,5 \%)$ em comparação com o grupo da gastrectomia laparoscópica (40;6,4\%). As complicações mais frequentes no grupo da gastrectomia aberta foram obstrução intestinal e infecção da incisão, provavelmente devido ao maior comprimento da incisão $(21,85 \pm 2,3 \mathrm{~cm})$ em comparação com o grupo da laparoscópica $(5,2 \pm 1,2 \mathrm{~cm})$. Já outras complicações 
não foram claramente diferentes entre os 2 grupos, como vazamento e sangramento do coto duodenal, sangramento intra-abdominal e abscesso. Um único estudo de nossa análise, discorreu sobre gastrectomia para a perfuração do câncer gástrico (PCG). Foram estudados 11 pacientes com PCG. A perfuração foi mais frequente no estádio III (8 pacientes) e no estádio IV (3 pacientes). Gastrectomia de emergência foi realizada em $8(72,8 \%)$ pacientes, sendo gastrectomia subtotal em 5 , gastrectomia total em 3 e fechamento simples com adesivo de omental em 3 . A taxa de mortalidade geral em 30 dias foi de $46 \%$. A sobrevida foi maior entre os pacientes submetidos à gastrectomia curativa do que naqueles submetidos ao fechamento simples com adesivo de omental. (IGNJATOVIC et al., 2016)

\section{DISCUSSÃO}

\section{FÍSTULA GÁSTRICA ANASTOMÓTICA APÓS GASTRECTOMIA VERTICAL}

Como visto em Resultados, a fístula gástrica anastomótica é a complicação mais comum após a gastrectomia vertical (GV) para obesidade. Trata-se de uma complicação temida pelos cirurgiões, pelo risco de morbidade e mortalidade que acrescenta, alta taxa de recidiva e dificuldade de tratamento. Diversos fatores podem levar à deiscência e à fistulização da linha de grampos e sutura de uma gastrectomia vertical. Processos isquêmicos, retração ou deformidade anatômica cicatricial, obstrução distal iatrogênica, resultando em abertura e vazamento quando a pressão intraluminal ultrapassa a complacência da linha de sutura, uso inadequado do instrumental cirúrgico e erro técnico, são alguns fatores causais descritos por Chen et al (2009). Estudo de Yehoshua et al. (2008), analisou as medidas da pressão e volume do estômago e da bolsa gástrica. Foi demonstrado que a distensão da bolsa gástrica formada após a GV é dez vezes menor do que a complacência do estômago por completo. Diante disso, pode-se inferir que processo mecânico de aumento da pressão intraluminal configura-se como importante fator etiológico para a ocorrência de deiscência e fístulização. Com a deiscência, a secreção flui pelo orifício e espalhase pela cavidade, sobretudo na região subdiafragmática, podendo resultar em sepse 
de foco abdominal, complicações pulmonares, principalmente à esquerda, em fístula gastrocutânea ou, em alguns casos, em fístula gastrobrônquica. (Correia, 2014).

Acerca do quadro clínico da fístula gástrica, em nossa revisão, encontramos que a dor abdominal e a peritonite foram os achados diagnósticos de apresentação, provavelmente pela contaminação da cavidade peritoneal pelo conteúdo intraluminal. Entretanto Jurowich et al. (2011), descrevem 4 casos de fístulas entre 45 pacientes submetidos a gastrectomia vertical laparoscópica, em que nenhum deles apresentou quadro de dor abdominal ou peritonite, e sim sinais e sintomas inespecíficos, como taquicardia, taquipnéia, febre, além de leucocitose e elevação dos níveis de proteína $C$ reativa. A ausência de sintomas mais específicos, de dor abdominal e de peritonite, pode dificultar o diagnóstico em caráter precoce. Dos 4 casos, 3 foram submetidos a reoperação, nos quais foi realizado ressíntese da linha de grampeamento, invaginação do orifício fistuloso, limpeza e drenagem da cavidade peritoneal.

Segundo Correia (2014), o tratamento conservador é realizado por meio de antiobioticoterapia endovenosa, nutrição parenteral total e uso de inibidor de bomba de prótons (IBP). Pode ser empregado quando não há indicação absoluta de reabordagem, ou seja, em pacientes hemodinamicamente estável e sem sinais de peritonite. Essa modalidade terapêutica tem resultados conflitantes e pode ser onerosa para o serviço de saúde, uma vez que exige longo período de permanência hospitalar, fatores que influenciam muitos cirurgiões a optarem pela reoperação. $O$ tratamento cirúrgico é mandatório quando há instabilidade hemodinâmica ou peritonite, e objetiva principalmente a lavagem da cavidade abdominal e a colocação do dreno cavitário próximo ao local da fístula. Em alguns casos, jejunostomia é realizada para alimentação enteral, uma vez que a nutrição parenteral total pode resultar em atrofia intestinal e translocação bacteriana, além de predispor a íleo paralítico e obstrução, entre outras complicações. Reoperação para reparo de fístula tem alta taxa de recidiva, pois o processo inflamatório tecidual intenso já instalado e pressão intraluminal elevada são fatores que permanecem contribuindo ativamente para a abertura do orifício. Com o objetivo de reduzir a incidência de deiscência, vazamentos e fístula, Correia (2014) e equipe realizam sobressutura das linhas de 
grampos em duas camadas. Porém, outros estudos relatam que essa medida não diminui a chance de ocorrência de vazamento, levando apenas a um aumento do tempo cirúrgico e dos custos, motivo pelo qual não é realizado de rotina. (JUROWICH et al., 2011).

\section{FÍSTULA DO COTO DUODENAL APÓS GASTRECTOMIA PARA CÂNCER GÁSTRICO}

Conforme apresentado anteriormente por dois estudos incluídos na revisão, a fístula do coto duodenal é uma das complicações mais graves e incomuns das gastrectomias para câncer gástrico. Fatores relacionados às diversas complicações das ressecções gástricas por malignidade são elucidados em diferentes trabalhos. Em nossa revisão, o número de leucócitos, o valor de PCR e albumina, foram apresentados por dois estudos, como sendo significativamente associados às complicações pós-operatórias.

Em uma análise multicêntrica retrospectiva, realizada em 11 unidades cirúrgicas da Itália, Cozzaglio et al. (2010), encontraram incidência de 1,8\% de fístula do coto duodenal, correspondendo a 68 casos dentre 3.785 gastrectomias totais e subtotais realizadas entre 1991-2006 para o tratamento do câncer gástrico. Idade entre 60 a 83 anos, níveis baixos de albumina sérica, complicações pós-operatórias e reintervenções foram fatores associados à mortalidade. Orsenigo et al. (2014), por sua vez, relataram 32 casos $(2,5 \%)$ de fístula do coto duodenal dentre 1.287 gastrectomias realizadas. Comorbidades, como cardiopatias e cirrose hepática, leucocitose préoperatória, estado nutricional deteriorado e dificuldades técnicas cirúrgicas, como ausência de reforço manual no coto duodenal e perda sanguínea $>300 \mathrm{ml}$, foram fatores de risco para a formação de fístula do coto duodenal e outras complicações.

\section{FATORES NUTRICIONAIS E METABÓLICOS RELACIONADOS AO PACIENTE}

O estudo de Zhang et al. (2018) incluído em nossa análise, apontou sarcopenia, miosteatose e obesidade visceral como importantes fatores preditivos de complicações pós-operatórias e que afetam a nutrição pós-operatória e o estado de 
inflamação de pacientes com câncer gástrico. Ilias; Kassab e Castro (2002) analisaram o efeito da obesidade nas complicações pós-operatórias e na sobrevida após cirurgia para câncer gástrico. Foram divididos 293 pacientes submetidos a gastrectomia por malignidade em três grupos, de acordo com o índice de massa corpórea (IMC), sendo o grupo A composto por pacientes com IMC $<20$, o grupo $B$ com $I M C$ entre 20 e 25 e o grupo $C$ com IMC $>25$. O tempo cirúrgico e a perda sanguínea foram maiores quanto maior fosse o IMC. As complicações pós-operatórias (fístula, abscesso e sangramento) foram de $3,3 \%$ no grupo $A, 5,6 \%$ no grupo $B$ e $22,2 \%$ no grupo $\mathrm{C}$. Assim, quanto maior o IMC de pacientes com câncer gástrico submetidos à cirurgia, maior o risco de complicações perioperatórias. Não houve diferença significativa na taxa de sobrevida em cinco anos entre os três grupos.

Myers et al. (2002) publicaram um estudo no The New England Journal of Medicine, no qual avaliaram a capacidade física de 6213 homens e o valor preditivo desse parâmetro para alguns aspectos clínico-cirúrgicos de interesse. Viu-se que a capacidade física avaliada pelo teste ergométrico é um importante preditor de risco de morte, em indivíduos saudáveis ou não, e que a capacidade física de pico é o melhor preditor da ocorrência de morte, seguido do número de maços de cigarro por ano, em indivíduos saudáveis. O risco relativo de morte é 4,5 vezes maior nos indivíduos saudáveis com a menor capacidade de exercício de pico em relação aos indivíduos com a mais alta capacidade. $O$ aumento de uma unidade no equivalente metabólico (MET), importante item das avaliações pré-operatórias, eleva em $12 \%$ a chance de sobrevivência de indivíduos saudáveis e pacientes com doença cardiovascular. Dentre os pacientes com doenças cardiovasculares, aqueles pertencentes ao mais baixo quintil de capacidade de exercício de pico têm um risco relativo de morte 4,1 vezes maior que os pertencentes ao mais alto quintil de capacidade de exercício. Assim, IMC, estado nutricional e capacidade física são 3 importantes indicativos de que o paciente suportará ou não o trauma cirúrgico e todas as alterações endocrinometabólicas, imunológicas e inflamatórias decorrentes dele. Portanto, configuram-se como fatores preditivos de complicações precoces das gastrectomias e merecem especial atenção e manejo, para evitar eventos adversos e diminuir a morbimortalidade. 


\section{DIA DA SEMANA NO QUAL É REALIZADA A CIRURGIA}

Tratando-se da análise retrospectiva de Li et al. (2017), os pacientes operados nos últimos dias da semana tiveram maior risco em relação à frequência e à gravidade das complicações pós-operatórias. As complicações graves (Graus III e IV de ClavienDindo) incidiram principalmente na quinta ou sexta-feira. Segundo Duarte (2007), a técnica empregada no procedimento cirúrgico, gastrectomia total ou subtotal, não apresenta significância quanto às complicações pós-operatórias. No entanto, a experiência da equipe cirúrgica e o bom acompanhamento pré e pós-operatório influenciam positivamente e de modo significativo nas morbidades e mortalidade dos pacientes submetidos à gastrectomias, independentemente da técnica operatória utilizada. Diante disso, por muitas vezes não haver o devido acompanhamento e vigília dos pacientes durante os finais da semana, fatores preditivos de complicações podem passar despercebidos, não permitindo intervir sobre eles. Ademais, as próprias complicações pós-operatórias podem ter diagnóstico tardio, em virtude da ausência ou da menor quantidade de profissionais em serviço, da demora da liberação de resultados de exames, entre outros fatores.

\section{GASTRECTOMIA RADICAL ABERTA VERSUS LAPAROSCÓPICA}

Em nosso estudo, relatamos que Hao et al. (2016) comparou os resultados das gastrectomias radicais aberta e laparoscópica. Confirmando resultados de estudos anteriores, as complicações pós-operatórias foram mais comuns no grupo da gastrectomia aberta $(61 ; 10,5 \%)$ em comparação com o grupo da gastrectomia laparoscópica $(40 ; 6,4 \%)$. Panduro et al. também relataram menor índice de complicações nos pacientes submetidos à cirurgia laparoscópica em relação à cirurgia aberta, porém, não houve diferença significativa em relação à sobrevida. No estudo de Sánchez et al (2019), viu-se que os pacientes submetidos à gastrectomia laparoscópica apresentaram menos sangramento intra-operatório, menos dor no pósoperatório e menor tempo de internação. 


\section{COMPLICAÇÕES GERAIS E FATORES RELACIONADOS}

Como evidenciado na presente revisão, Zhang et al. (2018) mostraram que 29 dos 278 pacientes $(10,4 \%)$ submetidos à gastrectomia laparoscópica para câncer, desenvolveram complicações maiores (grau $\geq$ III da classificação de ClavienDindo). Dentre as complicações, 9 cursaram com vazamento anastomótico, $6 \mathrm{com}$ abscesso intra-abdominal ou coleções de fluidos, $3 \mathrm{com}$ derrames pleurais, $4 \mathrm{com}$ pneumonia, $3 \mathrm{com}$ fístulas pancreáticas, $2 \mathrm{com}$ complicações de feridas e $2 \mathrm{com}$ fístulas no coto. Ruiz et al. (2004) apontam em seu estudo que as complicações após gastrectomias também consistiram em fístulas, como as esofagojejunais, gastrojejunais e duodenais, além de infecções respiratórias, abscessos intraabdominais, fístula pancreática, obstrução intestinal, hemorragia na anastomose e infecção da ferida cirúrgica. Já quanto ao risco de mortalidade intra-hospitalar, esta esteve intimamente relacionada com variáveis como hipoalbuminemia, transfusão sanguínea, esplenectomia e re-ressecção. A literatura existente sobre as diversas complicações de gastrectomias totais e subtotais também elenca fístulas anastomóticas, fístula de coto duodenal, hemoperitônio, infecções pulmonares e obstrução intestinal como complicações pós-operatórias mais recorrentes. Contudo, apesar de a morbidade descrita ser a quase a mesma, desde as primeiras cirurgias realizadas e independente da técnica operatória aplicada, a mortalidade associada às gastrectomias vem diminuindo significativamente, devido aos avanços no aprimoramento dos procedimentos cirúrgicos, nos cuidados pré e pós-operatórios e nas intervenções oportunas e eficazes frente às complicações.

\section{FATORES ASSOCIADOS E COMPLICAÇÕES PÓS-OPERATÓRIAS NO PACIENTE COM CÂNCER GÁSTRICO E RELAÇÃo COM A SOBREVIDA A LONGO PRAZO}

Coorte retrospectiva incluída em nossa revisão, com 112 pacientes submetidos à gastrectomia total, subtotal ou total estendida, para câncer, revelou uma taxa de complicações graves ( $\geq \mathrm{IIla}$ ) de $14 \%$ e taxa de mortalidade de $1,8 \%$. Idade $>65$ anos, ASA 3 ou superior, insuficiência renal crônica, ressecção de múltiplos órgãos e tumor, 
nódulo e metástases (TNM) estágio $\geq$ IIIc foram significativamente associados com maior grau de complicação. (NEVO et al., 2018). Outra análise retrospectiva de Norero et al. (2019), incluiu pacientes tratados com gastrectomia para câncer gástrico ou JEG (junção esofagogástrica). A frequência de complicações graves foi significativamente maior nos pacientes com câncer de estadio T3/T4 de JEG, atingindo $26 \%$ em relação ao grupo de casos não-JEG. No estadio T1/T2 houve apenas $4 \%$ de complicações graves. Estudos sobre câncer de esôfago e cólon concluíram que as complicações pós-operatórias estão relacionadas à pior sobrevida oncológica de modo independente. Nos casos de câncer gástrico, ainda não está esclarecida a influência das complicações pós-operatórias com relação à sobrevida em longo prazo. É necessário que haja um acompanhamento longitudinal desses pacientes com câncer gástrico submetidos à gastrectomia, para definir se as diversas complicações pósoperatórias associadas a esse procedimento, sejam elas gerais, infecciosas, graves ou não, alteraram a sobrevida.

\section{CONCLUSÃO}

Diante dos achados da literatura relatados na presente revisão, as gastrectomias são cirurgias de grande porte, frequentemente realizadas, e passíveis de complicações maiores, como fístula anastomótica ou deiscência da ferida, apresentando-se com peritonite, complicação precoce mais comum, além de abscesso intra-abdominal ou coleções de fluidos, derrames pleurais, pneumonia, fístulas pancreáticas, complicações de feridas, fístulas do coto, entre outras. Diante disso, salienta-se a importância do treinamento dos cirurgiões e do conhecimento acerca das complicações pós-operatórias de gastrectomias, para que possam reconhecer prontamente e tratar oportunamente, elevando a sobrevida dos pacientes submetidos a esses procedimentos.

Os fatores mais comumente associados a complicações foram como idade $>60$ anos, cirurgia aberta, estágio avançado do câncer gástrico (III-IV), uso pós-operatório de opióide, valor de PCR, relação PRC/albumina, estado nutricional, dia da semana em que é realizada a cirurgia, entre outros. Dessa forma, o conhecimento dos fatores preditivos e a presença deles deve alertar o médico para o surgimento de 
complicações pós-operatórias. Os fatores descritos foram fortemente entrelaçados com tais eventos, tornando a predição um importante fator para a vigilância e intervenção frente à essas intercorrências. Diante do exposto, as gastrectomias por câncer gástrico realizadas nos últimos dias da semana têm maior risco de complicações pós-operatórias mais graves (Graus III e IV de Clavien-Dindo) incidindo principalmente na quinta ou sexta-feira, o que mostra o impacto da observação do paciente e dos cuidados perioperatórios adequados, mais negligenciados aos finais de semana, na redução da taxa de complicações. Relatou-se, também, o aumento das taxas de complicações pós-operatórias devido ao comprometimento da nutrição pós-operatória e do estado de inflamação, estando relacionadas com a sarcopenia, miosteatose e obesidade visceral, reforçando a importância do estado nutricional e da nutrição perioperatória nas gastrectomias e em cirurgias em geral. Diante desses principais achados do presente estudo, reforça-se a relevância de os cirurgiões conhecerem as complicações das gastrectomias, em termos de frequência e gravidade, e os fatores preditivos mais comumente associados a elas, além de realizarem um adequado acompanhamento perioperatório do paciente, desde o preparo pré-operatório até a vigilância pós-cirúrgica, a fim de evitar essas intercorrências ou de reconhecê-las e tratá-las oportunamente, elevando sobremaneira a sobrevida dos pacientes.

\section{REFERÊNCIAS}

AIOLFI, A. et al. Impact of spleen-preserving total gastrectomy on postoperative infectious complications and 5-year overall survival: systematic review and metaanalysis of contemporary randomized clinical trials. Current Oncology, v. 26, n. 2, p. e202, 2019.

ANDREOLLO, Nelson Adami; LOPES, Luiz Roberto; COELHO NETO, João de Souza. Complicações pós-operatórias após gastrectomia total no câncer gástrico: análise de 300 doentes. ABCD, arq. bras. cir. dig., São Paulo, v. 24, n. 2, p. 126130 , June 2011. Available from

$<$ http://www.scielo.br/scielo.php?script=sci_arttextHYPERLINK "http://www.scielo.br/scielo.php?script=sci_arttext\&pid=S0102- 
67202011000200007\&lng=en\&nrm=iso"\&HYPERLINK

"http://www.scielo.br/scielo.php?script=sci_arttext\&pid=S0102-

$67202011000200007 \&$ Ing=en\&nrm=iso"pid=S0102-

67202011000200007HYPERLINK

"http://www.scielo.br/scielo.php?script=sci_arttext\&pid=S0102-

67202011000200007\&lng=en\&nrm=iso"\&HYPERLINK

"http://www.scielo.br/scielo.php?script=sci_arttext\&pid=S0102-

$67202011000200007 \&$ Ing=en\&nrm=iso"Ing=enHYPERLINK

"http://www.scielo.br/scielo.php?script=sci_arttext\&pid=S0102-

67202011000200007\&Ing=en\&nrm=iso"\&HYPERLINK

"http://www.scielo.br/scielo.php?script=sci_arttext\&pid=S0102-

$67202011000200007 \&$ Ing=en\&nrm=iso"nrm=iso $>$.

access

on 24 Aug. 2020. https://doi.org/10.1590/S0102-67202011000200007.

BRANCO-FILHO, Alcides José et al. Tratamento da obesidade mórbida com gastrectomia vertical. $A B C D$, arq. bras. cir. dig., São Paulo , v. 24 , n. 1, p. 5254, Mar. 2011. Available from $<$ http://www.scielo.br/scielo.php?script=sci_arttextHYPERLINK "http://www.scielo.br/scielo.php?script=sci_arttext\&pid=S0102-

67202011000100011\&lng=en\&nrm=iso"\&HYPERLINK

"http://www.scielo.br/scielo.php?script=sci_arttext\&pid=S0102-

$67202011000100011 \&$ Ing=en\&nrm=iso"pid=S0102-

67202011000100011HYPERLINK

"http://www.scielo.br/scielo.php?script=sci_arttext\&pid=S0102-

$67202011000100011 \&$ Ing=en\&nrm=iso"\&HYPERLINK

"http://www.scielo.br/scielo.php?script=sci_arttext\&pid=S0102-

$67202011000100011 \&$ Ing=en\&nrm=iso"Ing=enHYPERLINK

"http://www.scielo.br/scielo.php?script=sci_arttext\&pid=S0102-

67202011000100011\&lng=en\&nrm=iso"\&HYPERLINK

"http://www.scielo.br/scielo.php?script=sci_arttext\&pid=S0102-

$67202011000100011 \&$ Ing=en\&nrm=iso"nrm=iso $>$.

access

on 24 Aug. 2020. http://dx.doi.org/10.1590/S0102-67202011000100011. 
CHEN, Bo et al. Reinforcement does not necessarily reduce the rate of staple line leaks after sleeve gastrectomy. A review of the literature and clinical experiences. Obesity surgery, v. 19, n. 2, p. 166-172, 2009.

CORREIA, Sércio Flavny Brandão de Menezes. Fístula e estenose em gastrectomia vertical: dilatação endoscópica, colocação de prótese e septotomia gástrica. Dissertação de Mestrado. Universidade Federal de Pernambuco. 2014.

COZZAGLIO, Luca et al. Duodenal fistula after elective gastrectomy for malignant disease. Journal of gastrointestinal surgery, v. 14, n. 5, p. 805-811, 2010.

DAPRI, Giovanni; CADIÈRE, Guy Bernard; HIMPENS, Jacques. Laparoscopic reconversion of Roux-en-Y gastric bypass to original anatomy: technique and preliminary outcomes. Obesity surgery, v. 21, n. 8, p. 1289-1295, 2011.

DE LOS ÁNGELES CORNEJO, María et al. Duodenal fistula after gastrectomy: retrospective study of 13 new cases. REVISTA ESPAñOLA DE ENFERMEDADES DIGESTIVAS, v. 2016, n. 108/1, p. 20-26, 2016.

DUARTE, Marcos et al. Correlação entre o anatomopatológico, a técnica operatória e as complicações pós-operatórias imediatas, dos casos de câncer gástrico operados no Hospital Florianópolis. 2007.

GARCÍA-DÍAZ, Juan José et al. Resultados, controversias, y volumen gástrico después de la gastrectomía vertical laparoscópica en el tratamiento de la obesidad. Cirugía y Cirujanos, v. 84, n. 5, p. 369-375, 2016.

HANS, Pankaj Kumar et al. Long-term outcome of laparoscopic sleeve gastrectomy from a single center in mainland China. Asian Journal of Surgery, v. 41, n. 3, p. 285-290, 2018.

$\mathrm{HAO}$, Yingxue et al. Comparison of laparoscopy-assisted and open radical gastrectomy for advanced gastric cancer: a retrospective study in a single minimally invasive surgery center. Medicine, v. 95, n. 25, 2016. 
IGNJATOVIC, Nebojsa et al. Perforation of gastric cancer-What should the surgeon do?. Bosnian journal of basic medical sciences, v. 16, n. 3, p. 222, 2016.

ILIAS, Elias Jirjoss. Qual o papel da gastrectomia no tratamento da úlcera péptica na atualidade?. Rev. Assoc. Med. Bras. São Paulo, v. 57, n. 1, pág. 9, fevereiro de 2011. Disponível em <http://www.scielo.br/scielo.php?script=sci_arttextHYPERLINK "http://www.scielo.br/scielo.php?script=sci_arttext\&pid=S0104-

42302011000100005\&lng=en\&nrm=iso"\&HYPERLINK

"http://www.scielo.br/scielo.php?script=sci_arttext\&pid=S0104-

42302011000100005\&lng=en\&nrm=iso"pid=S0104-

42302011000100005HYPERLINK

"http://www.scielo.br/scielo.php?script=sci_arttext\&pid=S0104-

42302011000100005\&lng=en\&nrm=iso"\&HYPERLINK

"http://www.scielo.br/scielo.php?script=sci_arttext\&pid=S0104-

42302011000100005\&lng=en\&nrm=iso"Ing=enHYPERLINK

"http://www.scielo.br/scielo.php?script=sci_arttext\&pid=S0104-

42302011000100005\&lng=en\&nrm=iso"\&HYPERLINK

"http://www.scielo.br/scielo.php?script=sci_arttext\&pid=S0104-

42302011000100005\&Ing=en\&nrm=iso"nrm=iso >. acesso em 24 de agosto de 2020. https://doi.org/10.1590/S0104-42302011000100005 .

ILIAS, Elias Jirjoss; KASSAB, Paulo; CASTRO, Osvaldo Prado. Complicações na gastrectomia por câncer e obesidade. Revista da Associação Médica Brasileira, v. 48, n. 3, p. 184-184, 2002.

JUROWICH, Christian et al. Gastric leakage after sleeve gastrectomy-clinical presentation and therapeutic options. Langenbeck's archives of surgery, v. 396, n. 7, p. 981, 2011.

KASSIR, Radwan et al. Complications of bariatric surgery: presentation and emergency management. 2016. 
LI, Rong et al. Weekday of surgery affects postoperative complications and longterm survival of Chinese gastric cancer patients after curative gastrectomy. BioMed research international, v. 2017, 2017.

LIANG, Wen-Quan et al. Nomogram to predict prolonged postoperative ileus after gastrectomy in gastric cancer. World journal of gastroenterology, v. 25, n. 38, p. 5838, 2019.

MAJOR, Piotr et al. Postoperative care and functional recovery after laparoscopic sleeve gastrectomy vs. laparoscopic Roux-en-Y gastric bypass among patients under ERAS protocol. Obesity surgery, v. 28, n. 4, p. 1031-1039, 2018.

MCHEIMECHE, Hussein et al. Double Baltazar procedure for repair of gastric leakage post-sleeve gastrectomy from two sites: case report of new surgical technique. Obesity surgery, v. 28, n. 7, p. 2092-2095, 2018.

MYERS, Jonathan et al. Exercise capacity and mortality among men referred for exercise testing. New England journal of medicine, v. 346, n. 11, p. 793-801, 2002.

NEVO, Yehonatan et al. Risk Factors for Complications of Total/Subtotal Gastrectomy for Gastric Cancer: Prospectively Collected, Based on the ClavienDindo Classification System. The Israel Medical Association journal: IMAJ, v. 5, n. 20, p. 277-280, 2018.

NORERO, Enrique et al. FATORES DE RISCO PARA COMPLICAÇÕES PÓSOPERATÓRIAS GRAVES APÓS GASTRECTOMIA POR CÂNCER DO ESTÔMAGO E JUNÇÃO ESOFAGOGÁSTRICA. ABCD, arq. bras. cir. dig., São Paulo , v. 32, n. 4, e1473, 2019 Available from

$<\mathrm{http}: / / w w w . s c i e l o . b r / s c i e l o . p h p ? s c r i p t=s c i$ arttextHYPERLINK

"http://www.scielo.br/scielo.php?script=sci_arttext\&pid=S0102-

67202019000400307\&Ing=en\&nrm=iso"\&HYPERLINK

"http://www.scielo.br/scielo.php?script=sci_arttext\&pid=S0102-

67202019000400307\&lng=en\&nrm=iso"pid=S0102-

67202019000400307HYPERLINK 
"http://www.scielo.br/scielo.php?script=sci_arttext\&pid=S0102-

67202019000400307\&Ing=en\&nrm=iso"\&HYPERLINK

"http://www.scielo.br/scielo.php?script=sci_arttext\&pid=S0102-

$67202019000400307 \&$ Ing=en\&nrm=iso"Ing=enHYPERLINK

"http://www.scielo.br/scielo.php?script=sci_arttext\&pid=S0102-

67202019000400307\&lng=en\&nrm=iso"\&HYPERLINK

"http://www.scielo.br/scielo.php?script=sci_arttext\&pid=S0102-

67202019000400307\&lng=en\&nrm=iso"nrm=iso > .

access

on 24 Aug. 2020. Epub Dec 20, 2019. https://doi.org/10.1590/01026720201HYPERLINK "https://doi.org/10.1590/0102-

672020190001e1473"90001e1473.

OLIVEIRA, Carolina Mantovani de et al. Factibility of open vertical gastrectomy in Brazil' s Public Health System. Revista do Colégio Brasileiro de Cirurgiões, v. 46, n. 6, 2019. Disponível em: http://www.facafisioterapia.net/2007/10/fisioterapiapneumofuncional-nas.html)

ORSENIGO, Elena et al. Duodenal stump fistula after gastric surgery for malignancies: a retrospective analysis of risk factors in a single centre experience. Gastric Cancer, v. 17, n. 4, p. 733-744, 2014.

PANDURO-CORREA, V. et al. Comparación de gastrectomía abierta frente a laparoscópica en cáncer gástrico avanzado. Revista de Gastroenterología de México, v. 85, n. 1, p. 32-41, 2020.

RUIZ, Eloy et al. Morbidade pós-operatória e mortalidade intra-hospitalar de gastrectomia de adenocarcinoma gástrico: análise de 50 anos. Rev. gastroenterol. Peru, Lima, v. 24, n. 3, pág. 197-210, jul., 2004.

SÁNCHEZ ZAPATA, José Antonio. Gastrectomía laparoscópica e incisional en pacientes con cáncer gástrico Hospital Nacional Arzobispo Loayza 2015-2017. 2019. 
SORIANO-GIMÉNEZ, Víctor et al. Infarto esplénico tardío tras gastrectomía vertical laparoscópica: a propósito de un caso. Cirugía y Cirujanos, v. 85, p. 80-83, 2017.

SUN, Feng et al. Postoperative C-reactive protein/albumin ratio as a novel predictor for short-term complications following gastrectomy of gastric cancer. World Journal of Surgical Oncology, v. 15, n. 1, p. 191, 2017.

VUOLO, Giuseppe et al. Is sleeve gastrectomy a therapeutic procedure for all obese patients?. International Journal of Surgery, v. 30, p. 48-55, 2016.

WANG, Xin et al. Effectiveness of laparoscopic sleeve gastrectomy for weight loss and obesity-associated co-morbidities: a 3-year outcome from Mainland Chinese patients. Surgery for Obesity and Related Diseases, v. 12, n. 7, p. 1305-1311, 2016.

WEN, Lei et al. Total vs. proximal gastrectomy for proximal gastric cancer: a systematic review and meta-analysis. Hepato-gastroenterology, v. 59, n. 114, p. 633640, 2012.

YEHOSHUA, Ronit $\mathrm{T}$. et al. Laparoscopic sleeve gastrectomy-volume and pressure assessment. Obesity surgery, v. 18, n. 9, p. 1083, 2008.

ZHANG, Kecheng et al. Ability of serum C-reactive protein concentrations to predict complications after laparoscopy-assisted gastrectomy: a prospective cohort study. Medicine, v. 95, n. 21, 2016.

ZHANG, Y. et al. Computed tomography-quantified body composition predicts short-term outcomes after gastrectomy in gastric cancer. Current Oncology, v. 25, n. 5, p. e411, 2018.

ZIZZO, Maurizio et al. Management of duodenal stump fistula after gastrectomy for malignant disease: a systematic review of the literature. BMC surgery, v. 19, n. 1, p. 55, 2019. 
Enviado: Setembro, 2020.

Aprovado: Outubro, 2020. 